\title{
Monotheism and Institutions in the Book of Chronicles
}

Temple, Priesthood, and Kingship in Post-Exilic Perspective. Studies of the Sofja Kovalevskaja Research Group on Early Jewish Monotheism. Vol. I

[Monotheismus und Institutionen in den Chronikbüchern.Tempel, Priestertum und Königtum in nach-exilischer Perspektive.]

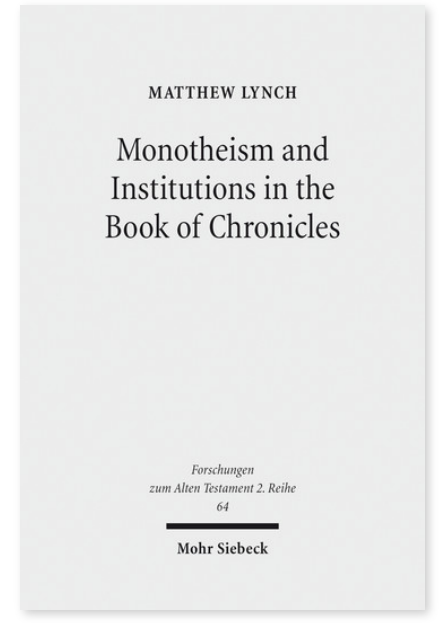

2014. X, 307 Seiten. FAT II 64

ISBN 978-3-16-152553-7

DOI 10.1628/978-3-16-152553-7

eBook PDF 104,00€

ISBN 978-3-16-152111-9

fadengeheftete Broschur 104,00€
Veröffentlicht auf Englisch.

Matthew Lynch untersucht, wie der eine Gott laut der Chronikbücherr durch Institutionen bekannt und erfahrbar wurde. Die Chronik stellt die bisherige Geschichte Israels aus dem Blickwinkel der starken Bindung an den Tempel und seine unterstützenden Institutionen (das Priestertum und das Königshaus) dar und beleuchtet die zahlreichen Wege, mit denen diese Institutionen göttliche Macht vermittelten und die nationale Einheit stärken. Indem sie so an der Wiederherstellung dieser Institutionen mitwirkt, bekräftigt die Chronik, dass die nach-exilischen Judäer sich, trotz des verarmten Lebensstandards dieser Zeit, mit dem mächtigen Gott ihrer Vergangenheit in Kontakt treten können. Die Chronik behauptet dennoch, dass Gott sich nicht nur denen verpflichtet fühlt, die am Tempeldienst beteiligt waren. Somit stellt sie einen Mittelweg zwischen den zwei vorherrschenden Blickwinkeln auf die Beziehung zwischen biblischem Monotheismus und Partikularismus dar.

Matthew Lynch Born 1979; 2001 BS in Biblical Studies; 2008 ThM in Old Testament; 2012 PhD in Religion/Hebrew Bible; currently research assistant at the Georg-August-Universität Göttingen and Adjunct Faculty Member at the Westminster Theological Centre in Cheltenham/UK.

Jetzt bestellen:

https://mohrsiebeck.com/buch/monotheism-and-institutions-in-the-book-of-chronicles-9783161525537?no_cache=1 order@mohrsiebeck.com

Telefon: $+49(0) 7071-923-17$

Telefax: $+49(0) 7071-51104$ 